\title{
A survey of aflatoxin $B_{1}$ in maize and awareness of aflatoxins in Vietnam
}

\author{
H.S. Lee ${ }^{1 *}$, H. Nguyen-Viet ${ }^{1}$, J. Lindahl ${ }^{2,3}$, H.M. Thanh ${ }^{4}$, T.N. Khanh ${ }^{4}$, L.T.T. Hien ${ }^{4}$ and D. Grace ${ }^{2}$ \\ ${ }^{1}$ International Livestock Research Institute (ILRI), Dept. of Food Safety and Zoonoses, Room 301-302, B1 Building, Van Phuc \\ Diplomatic Compound, 298 Kim Ma Street, Ba Dinh District, Hanoi 00100, Vietnam; ${ }^{2}$ International Livestock Research \\ Institute (ILRI), Dept. of Food Safety and Zoonoses, 30709 Naivasha Rd, Nairobi, Kenya; ${ }^{3}$ Swedish University of Agricultural \\ Sciences, Institutionen för kliniska vetenskaper, P.O. Box 7054, 75007 Uppsala, Sweden; ${ }^{4}$ Plant Protection Research Institute \\ (PPRI), Duc thang commune, Dong Ngac, Tu Liem District, Hanoi 084, Vietnam; h.s.lee@cgiar.org
}

Received: 27 September 2016 / Accepted: 4 November 2016

(c) 2017 Wageningen Academic Publishers

\section{OPEN ACCESS @) (1)(2) RESEARCH ARTICLE}

\begin{abstract}
Vietnam is a tropical country with high temperature and precipitation, which may provide good conditions for fungal growth. A few limited studies have been conducted to evaluate the level of aflatoxin $B_{1}$ in maize in Vietnam. In addition, no studies have been conducted to evaluate the perception and knowledge of aflatoxins in Vietnam. Therefore, the main objective of this study was to determine the levels of aflatoxin $B_{1}$ for human and animal consumption in maize and evaluate perceptions and knowledge of aflatoxins among people across the country. A total of 2,370 samples were collected from six provinces and analysed using ELISA. Among collected samples, 799 samples (33.71\%, 95\% confidence interval (CI): 31.81-35.66\%) and 687 samples (28.98\%, 95\%CI: 27.17-30.86\%) had levels above $2 \mu \mathrm{g} / \mathrm{kg}$ and $5 \mu \mathrm{g} / \mathrm{kg}$, respectively [range from below limit of detection (LOD) to $34.8 \mu \mathrm{g} / \mathrm{kg}$; of the samples above LOD, the mean was $13.1 \mu \mathrm{g} / \mathrm{kg}$ and median was $11.2 \mu \mathrm{g} / \mathrm{kg}$ ]. A total of 551 people were interviewed from 6 provinces. The survey showed that awareness of aflatoxins (question: Have you heard about aflatoxins?) in southern Vietnam [An Giang (25\%), Dak Lak (23.23\%) and Dong Nai (6\%)] was relatively higher than in provinces in northern Vietnam. We believe that this analysed information can be useful to better understand the epidemiology of aflatoxins in different provinces. This study also produces evidence on potential risk to humans and animals in Vietnam as well as demographic factors (such as gender and level of education) significantly influencing knowledge of aflatoxins. In conclusion, this paper points to the importance of raising the awareness of the risks with aflatoxins, bearing in mind the gender aspect during capacity development.
\end{abstract}

Keywords: Vietnam, ELISA, mycotoxins, aflatoxin $B_{1}$, survey, perception/knowledge

\section{Introduction}

Mycotoxins are secondary metabolites produced by fungi (Richard, 2007; Roebuck and Maxuitenko, 1993). The Food and Agriculture Organization (FAO) estimates that up to $25 \%$ crops globally are affected by mycotoxins each year (Devegowda et al., 1998; Smith et al., 1995). Aflatoxins are a group of mycotoxins, which are mainly produced by two fungi, Aspergillus flavus and Aspergillus parasiticus (Bennett and Klich, 2003; Peraica et al., 1999). The environmental conditions influence the growth of aflatoxins. For maize grown in the field, high risk factors are high temperature and drought stress, while during storage, high temperature and humidity along with improper storage practice increase the risk (Abbas et al., 2002, 2006; Magan and Aldred, 2007; Sandris and Magan, 2004).

The most important are aflatoxins $B_{1}, B_{2}, G_{1}$ and $G_{2}$ (Bennett and Klich, 2003). In particular, aflatoxin $B_{1}$ $\left(\mathrm{AFB}_{1}\right)$ is commonly detected in a wide range of food commodities (Goto et al., 1996; Klich et al., 2000). Maize and peanuts are at high risk for aflatoxin contamination (Bennett and Klich, 2003; Roebuck and Maxuitenko, 1993; Rustom, 1997; Thieu et al., 2008). Aflatoxins have been associated with both carcinogenic and hepatotoxic effects, depending on the level and duration of exposure (Lewis et al., 2005). According to the International Agency for Research on Cancer (IARC), aflatoxins are classified as 
group 1 carcinogens (IARC, 2002). It has been estimated that 4.5 billion people in developing countries are at risk of exposure to uncontrolled aflatoxins (Williams, 2011). While the greatest health burden is the result of chronic exposure, high doses of aflatoxins can also cause acute and fatal disease (Bennett and Klich, 2003; Eaton and Groopman, 2013). A major outbreak was reported in 2004 in rural Kenya, resulting in 317 cases and 125 deaths due to consumption of aflatoxin-contaminated maize (Lewis et al., 2005). Livestock can also be affected by exposure to aflatoxins and when they consume aflatoxins, $\mathrm{AFB}_{1}$ is converted to aflatoxin $M_{1}$ which can be carried over to livestock products, especially milk (Carvajal et al., 2003).

It is known that exposure to aflatoxins poses a threat to both human and animal health (Bennett and Klich, 2003; Williams et al., 2004). For humans, aflatoxins can cause illness and death, and chronic exposure can cause liver cancer (especially where hepatitis is prevalent); chronic exposure is also associated with immune suppression and stunted growth of children (Eaton and Groopman, 2013; Henry et al., 1999, 2002; Williams et al., 2004). For animals, high levels of aflatoxins can cause death. Chronic consumption of aflatoxins can be associated with decreased growth/production and reproductive issues (Binder et al., 2007; Mohammadi, 2011).

Vietnam is a tropical country with high temperature and precipitation which may provide good conditions for fungal growth (Trung et al., 2001; Wang et al., 1995). A few limited studies have been conducted to evaluate the level of $\mathrm{AFB}_{1}$ in maize in Vietnam. $\mathrm{AFB}_{1}$ was detected in 17 out of 25 samples (68\%) collected from North, Central and South Vietnam (Trung et al., 2008). Another study in North Vietnam found that 14 out of 15 samples were positive for $\mathrm{AFB}_{1}$, ranging between 9.4 and $96 \mu \mathrm{g} / \mathrm{kg}$ (Wang et al., 1995). In Southern Vietnam, a study showed that the positive rate for $\mathrm{AFB}_{1}$ was $91.7 \%$ (11/12) in maize for growing pigs and sows, with a mean concentration of $77.5 \mu \mathrm{g} / \mathrm{kg}$ (Thieu et al., 2008). However, those studies may not have had large enough sample sizes to properly evaluate the level of $\mathrm{AFB}_{1}$. In addition, no studies have been conducted to evaluate the perception and knowledge of aflatoxins in Vietnam. Therefore, the main objective of this study was to determine the levels of $\mathrm{AFB}_{1}$ in maize and evaluate perceptions and knowledge of aflatoxins among people across the country.

\section{Material and methods}

\section{Study locations and data collection}

This study was conducted in collaboration with the Plant Protection Research Institute (PPRI) under the Ministry of Agriculture and Rural Development (MARD) in Vietnam between 1 January and 30 April 2016. Maize samples (harvested in 2015) were collected from six provinces (Figure 1). The provinces were selected based on high maize production and one of the ecological zones and to represent 6 agro-ecological zones (Vietnam is commonly divided into 8 regions based on geographical features and weather condition). Within each province, 25 communes (16-18 samples per commune and $1 \mathrm{~kg}$ per sample) were

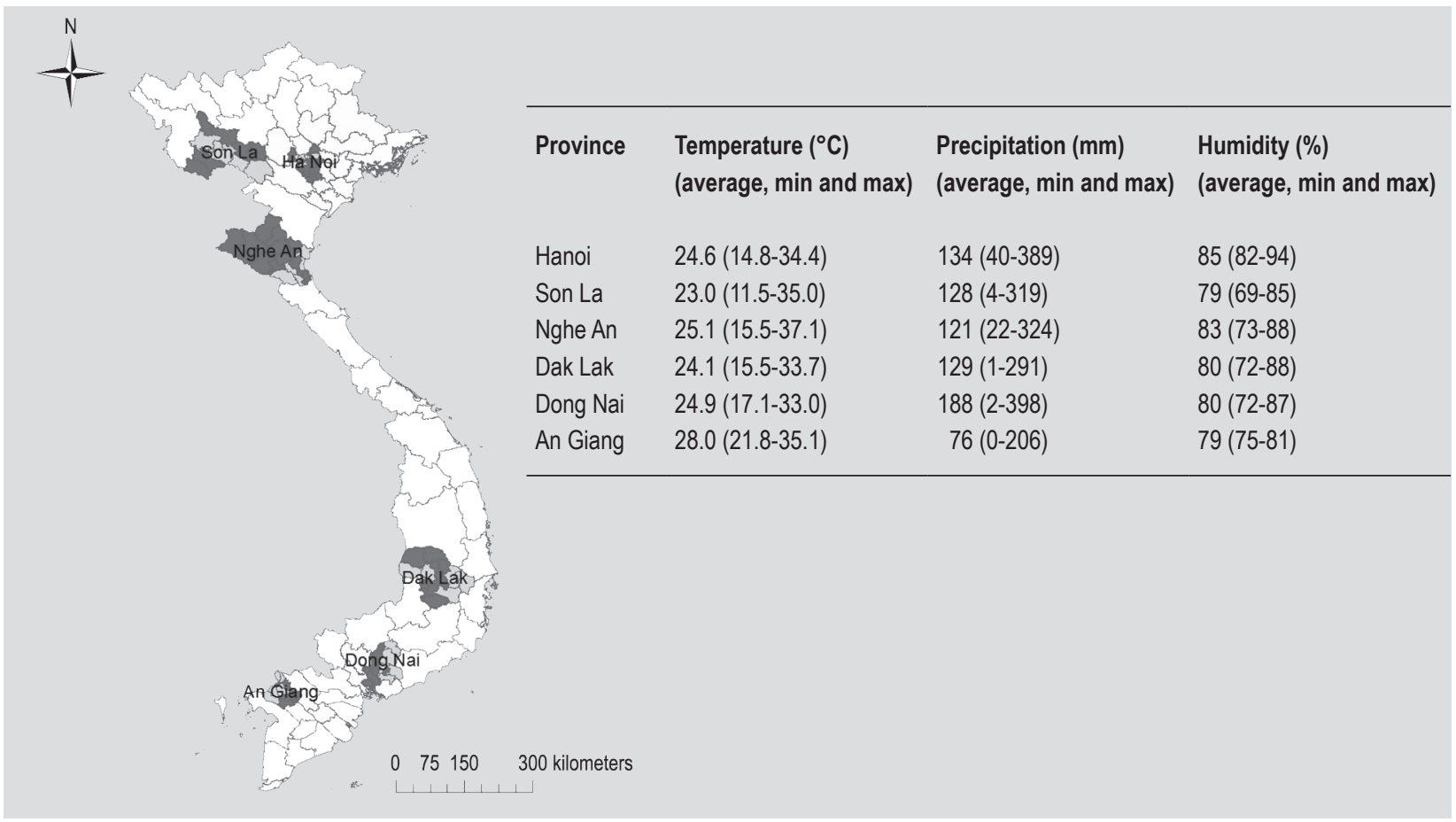

Figure 1. Sampling districts (light grey) within selected provinces (dark grey) and climate information. 
selected from five districts. Maize samples were collected from homes, markets and warehouses that were easily accessible in each location during the same visit. In each province at least 385 samples were collected. Sample size was based on $50 \%$ prevalence, a precision level of $5 \%$, and 95\% confidence interval (CI). Additional information on date of collection, purpose (human consumption or animal feed), and type of maize was collected through questionnaires. In parallel, a survey was conducted in order to better understand the perceptions and knowledge of aflatoxins among 551 people from six provinces using faceto-face interviews. All respondents were randomly selected (one sample per household) with multi-stage sampling (province-district-commune).

\section{Laboratory analysis}

The level was measured with a competitive $\mathrm{AFB}_{1}$ Low Matrix enzyme linked immune-sorbent assay (ELISA) (Helica Biosystems Inc., Santa Ana, CA, USA); according to the manufacturer the detection limit for this test was $0.02 \mu \mathrm{g} / \mathrm{kg}$ in undiluted samples. All samples were delivered from each province within 7 days and analysed in room temperature at PPRI in Hanoi. We followed the manufacturer's instructions; $\mathrm{AFB}_{1}$ was extracted from a ground sample with $80 \%$ methanol (1/5 dilution) and followed with $1 / 10$ dilution in phosphate-buffered saline prior to running the assay (a total of 1:50 dilution), giving a final limit of detection (LOD) of $1 \mu \mathrm{g} / \mathrm{kg}$ in samples. A regression curve was calculation based on the optical density (OD) values of the kits standards, and sample levels were determined based on the resulting equation.

\section{Data analysis}

According to the Vietnamese regulation, the action level for $\mathrm{AFB}_{1}$ in maize is $5 \mu \mathrm{g} / \mathrm{kg}$ for human consumption whereas there is no guideline for animal feed (FSI Vietnam, 2011). Within EU, the tolerated level for most foods is $2 \mu \mathrm{g} / \mathrm{kg}$, and for feedstuffs for dairy cattle $5 \mu \mathrm{g} / \mathrm{kg}$ (EC, 2006). The United States Food and Drug Administration (FDA) action guideline for total aflatoxins (aflatoxin $B_{1}, B_{2}, G_{1}$ and $G_{2}$ ) present in food or feed varies from $20 \mu \mathrm{g} / \mathrm{kg}$ to $300 \mu \mathrm{g} /$ $\mathrm{kg}$ depending on the type of food or feed and its purpose (FDA, 2015). The median tolerated levels $(\mu \mathrm{g} / \mathrm{kg})$ for $\mathrm{AFB}_{1}$ in foodstuffs and feedstuffs are 2 and $5 \mu \mathrm{g} / \mathrm{kg}$ around the world, respectively (FAO, 2004). For our analysis, the proportion of samples exceeding cut-off levels of $2 \mu \mathrm{g} / \mathrm{kg}$ and $5 \mu \mathrm{g} / \mathrm{kg}$ were calculated. In addition, mean, median and range were investigated for each province, with only samples exceeding LOD $(1 \mu \mathrm{g} / \mathrm{kg})$ included for calculation.

Demographic information collected in the survey included age ( $<20$ year, 20-29 years, 30-39 years, $40-49$ years, 50-59 years and $\geq 60$ years), sex (male and female), education level (none, primary/secondary school, high school and college/university or more) and occupation (farmers, retailers, feed manufactures and others). A multivariable logistic regression model was constructed with odds ratio (OR) and 95\% CI to evaluate the association between the demographic variables and awareness of aflatoxin (corresponding question with answer 'Have you heard about aflatoxins?'). In addition, the cluster effect (taking into account the reduced variation in samples from the same province compared to samples from different provinces) for provinces was incorporated into the model, by having province as a random effect. A subgroup with the lowest awareness (say 'no') was used as a reference in the model. The final logistic regression model was assessed for goodness-of-fit using the Hosmer-Lemeshow test (Hosmer et al., 1997). An alpha level of $<0.05$ was set for statistical significance. Lastly, other information from short-answer questions was summarised from questionnaires. All data were imported into Microsoft Excel 2010 (Microsoft, Redmond, WA, USA) and analysed using STATA (version 14.0; StataCorp, College Station, TX, USA). ArcGIS version 10.3.1 ArcMap (ESRI, Redlands, CA, USA) was used to create the map.

\section{Results}

A total of 2,370 samples were collected from homes, markets and warehouses from 6 provinces (Hanoi: $n=397$, Son La: $\mathrm{n}=395$, Nghe An: $\mathrm{n}=394$, Dak Lak: $\mathrm{n}=389$, Dong Nai: n=395 and An Giang: $n=400)$. Among collected samples, 799 samples (33.71\%, 95 CI: 31.81-35.66\%) and 687 samples (28.98\%, 95\%CI: 27.17-30.86\%) had levels above 2 and 5 $\mu \mathrm{g} / \mathrm{kg}$, respectively (range from below LOD to $34.8 \mu \mathrm{g} / \mathrm{kg}$; of the samples above LOD, the mean was $13.1 \mu \mathrm{g} / \mathrm{kg}$ and median was $11.2 \mu \mathrm{g} / \mathrm{kg})$. In Hanoi, maize samples were mainly collected from homes (68.77\%), followed by markets $(22.17 \%)$ and warehouses $(13.60 \%)$. The main purpose of maize was for animal feed (384 samples: $96.72 \%$ ) and food consumption (13 samples: 3.28\%) (Table 1). In Son La, maize samples were collected from homes (97.72\%) and warehouses (2.28\%) and all samples were used for feed. In Nghe An, samples were collected from homes (68.27\%), warehouses (16.49\%) and markets (15.41\%), respectively. The purpose of maize was feed (391 samples: 99.23\%) and food (3 samples: 0.73\%) (Table 1). In Dak Lak, samples were collected from home (100\%). Nearly half of the samples were used for food (189 samples: 48.59\%) and feed (200 samples: $51.41 \%$ ) (Table 1). In Dong Nai, samples were collected from homes only. Nearly half of the samples were used for food (194 samples: 49.11\%) and animal feed (201 samples: $50.89 \%$ ) (Table 1). In An Giang, almost all samples were collected from homes (99.25\%), with few from markets $(0.5 \%)$ and warehouses $(0.25 \%)$. Among collected samples, 131 (32.75\%) and 269 (67.25\%) samples were used for food and feed (Table 1). 
Table 1. Distribution of aflatoxin $B_{1}$ levels in maize for food and feed from six provinces.

\begin{tabular}{|c|c|c|c|c|c|c|}
\hline Province & Purpose (n) & $\begin{array}{l}\text { No. with aflatoxin level } \\
>2 \mu \mathrm{g} / \mathrm{kg} \\
(\% \text { with } 95 \% \mathrm{Cl})\end{array}$ & $\begin{array}{l}\text { No. with aflatoxin level } \\
>5 \mu \mathrm{g} / \mathrm{kg} \\
(\% \text { with } 95 \% \mathrm{Cl} \text { ) }\end{array}$ & Mean $^{1}$ & Median $^{1}$ & Range \\
\hline \multirow[t]{2}{*}{ Hanoi } & Human consumption (13) & $3(23.08 \%, 5.04-53.81)$ & $3(23 \%, 50.38-53.81)$ & 7.8 & 8.4 & $<$ LOD-13.2 \\
\hline & Animal feed (384) & $181(47.14 \%, 42.05-52.26)$ & $160(41.67 \%, 36.69-46.77)$ & 11.8 & 13.5 & $<$ LOD-34.8 \\
\hline \multirow[t]{2}{*}{ Son La } & Human consumption (0) & & & & & \\
\hline & Animal feed (395) & $230(58.23 \%, 53.19-63.14)$ & $203(51.39 \%, 46.34-56.42)$ & 12.0 & 14.3 & $<$ LOD-22.2 \\
\hline \multirow[t]{2}{*}{ Nghe An } & Human consumption (3) & $1(33.33 \%, 0.84-90.57)$ & $1(33.33 \%, 0.84-90.57)$ & 11.0 & 11.0 & $<$ LOD-11.0 \\
\hline & Animal feed (391) & $111(28.39 \%, 23.97-33.14)$ & $86(21.99 \%, 17.99-26.43)$ & 10.4 & 10.9 & $<$ LOD-30.0 \\
\hline \multirow[t]{2}{*}{ Dak Lak } & Human consumption (187) & $9(4.81 \%, 2.22-8.94)$ & $9(4.81 \%, 2.22-8.94)$ & 9.4 & 9.5 & $<\mathrm{LOD}-16.0$ \\
\hline & Animal feed (202) & $5(2.48 \%, 1.09-5.69)$ & $4(1.98 \%, 0.54-4.99)$ & 8.2 & 5.89 & $<$ LOD-19.3 \\
\hline \multirow[t]{2}{*}{ Dong Nai } & Human consumption (194) & $86(44.33 \%, 37.22-51.62)$ & $68(35.05 \%, 28.36-42.21)$ & 11.2 & 14 & $<$ LOD-20.9 \\
\hline & Animal feed (201) & $103(51.24 \%, 44.11-58.34)$ & $89(44.28 \%, 37.29-51.44)$ & 11.7 & 13.6 & $<$ LOD-22.0 \\
\hline \multirow[t]{2}{*}{ An Giang } & Human consumption (131) & $43(32.82 \%, 24.88-41.57)$ & $41(31.06 \%, 23.30-39.70)$ & 10.4 & 10.2 & $<$ LOD-21.8 \\
\hline & Animal feed (269) & $27(10.04 \%, 6.72-14.27)$ & $23(8.55 \%, 5.50-12.55)$ & 7.0 & 5.5 & $<$ LOD-23.8 \\
\hline
\end{tabular}

For the survey, a total of 551 people were interviewed from 6 provinces Hanoi: $n=80$, Son La: $n=92$, Nghe An: n=80, Dak Lak: $n=100$, Dong Nai: $n=100$ and An Giang: $\mathrm{n}=100$ ). The survey showed that awareness of aflatoxins (question: Have you heard about aflatoxins?) in southern Vietnam [An Giang (25\%), Dak Lak (23.23\%) and Dong Nai (6\%)] was relatively higher than provinces in northern Vietnam (Figure 2). Awareness in age groups 20-29, 3039 and 50-59 was relatively high (Table 2). In addition, males, better educated individuals (collage/university or more), people of the 'other' occupational group (e.g. office workers, businessman, etc.) were more aware of aflatoxins

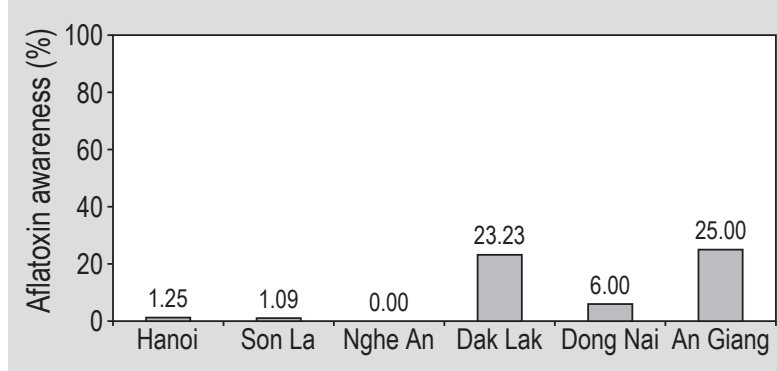

Figure 2. Awareness of aflatoxins by each province (Question: 'Have you heard about aflatoxins?').

Table 2. Demographic characteristics of survey respondents from 'Have you heard about aflatoxins?'.

$\begin{array}{llc}\text { Category } & \text { Characteristic }(n) & \text { Have you heard about aflatoxins? } \\ \text { Age (year) } & <20(n=1) & 0 \\ & 21-29(n=29) & 8(27.6 \%) \\ & 30-39(n=74) & 10(13.5 \%) \\ & 40-49(n=105) & 2(1.9 \%) \\ \text { Sex } & 50-59(n=290) & 31(10.7 \%) \\ & \geq 60(n=52) & 4(7.7 \%) \\ \text { Education } & \text { male }(n=381) & 46(12.1 \%) \\ & \text { female }(n=170) & 10(5.9 \%) \\ & \text { none }(n=2) & 0 \\ \text { primary \& middle school }(n=404) & 36(8.9 \%) \\ \text { Occupation } & \text { high school (n=107) } & 4(3.7 \%) \\ & \text { college/university or more (n=38) } & 16(59.3 \%) \\ & \text { farmers }(n=493) & 40(8.1 \%) \\ & \text { retailers }(n=25) & 4(16.0 \%) \\ & \text { feed manufacturers ( } n=3) & 0 \\ & \text { others (office workers and businessmen) }(n=30) & 12(40.0 \%)\end{array}$


(Table 2). The multivariable analysis showed that age groups 21-29 (OR: 9.74, $P<0.001$ ) and 50-59 (OR: 5.15, $P<0.003$ ) had a significantly higher awareness compared to the reference group (group 40-49). Male (OR: 2.56, $P<0.012$ ) and education at colleague/university or higher level (OR: $11.79, P<0.001)$ had a significantly increased awareness compared to the reference groups (female and primary/ secondary school) (Table 3). The occupation variable was not significant in the model. The Hosmer-Lemeshow tests showed that the current model did not violate the assumptions of goodness-of-fit. Overall, more than 50\% of people did not believe that aflatoxins pose health risks to humans and animals (Table 4).

\section{Discussion}

This study aimed to evaluate $\mathrm{AFB}_{1}$ in maize across the country during the study period. We found that Son La had highest positive rates for feed, whereas Dak Lak exhibited lower positive rates than other provinces. In Hanoi, the presence of $\mathrm{AFB}_{1}$ was investigated in maize for pig feed by Wang et al (1995) with a high positive rate (93.33\%) reported, ranging between $9.4 \mu \mathrm{g} / \mathrm{kg}$ and $96 \mu \mathrm{g} / \mathrm{kg}$. However, our study showed a relatively low positive rate and low $\mu \mathrm{g} / \mathrm{kg}$ levels were detected for feed in Hanoi. Another study from southern Vietnam showed that positive rate for $\mathrm{AFB}_{1}$ in maize was $91.7 \%$ (11/12), ranging from $0.4 \mu \mathrm{g} / \mathrm{kg}$ to $555 \mu \mathrm{g} /$ $\mathrm{kg}$ (median: $77.5 \mu \mathrm{g} / \mathrm{kg}$ ) which was higher than our results (Thieu et al., 2008). Overall, $\mu \mathrm{g} / \mathrm{kg}$ levels for mean, median and range were relatively low compared with the previous studies (Thieu et al., 2008; Trung et al., 2008; Wang et al., 1995). It might be possible that improved techniques or facilities for storing maize have played a role in mitigating aflatoxins over time or it might be related to timing of sampling depending on the areas. Also because mycotoxin concentrations show an extremely skewed distribution in foods and feeds, sampling variation across studies is common (Pitt et al., 2012).

Table 3. Final multivariable logistic regression model of awareness of aflatoxins from 6 provinces in Vietnam (question: 'Have you heard about aflatoxins?)'.1

\begin{tabular}{|c|c|c|c|c|}
\hline Variable & Category & Odds ratio & $95 \% \mathrm{Cl}$ & $P$-value \\
\hline \multirow[t]{6}{*}{ Age (year) } & $<20$ & none & none & none \\
\hline & $21-29$ & 9.7 & $5.2-18.4$ & $<0.001^{*}$ \\
\hline & $30-39$ & 4.7 & $1.8-12.2$ & $0.001^{*}$ \\
\hline & $40-49$ & reference & $\mathrm{N} / \mathrm{A}$ & $\mathrm{N} / \mathrm{A}$ \\
\hline & $50-59$ & 5.2 & $1.7-15.3$ & $0.003^{*}$ \\
\hline & $\geq 60$ & 4.1 & $0.4-47.4$ & 0.264 \\
\hline \multirow[t]{2}{*}{ Sex } & male & 2.6 & $1.1-5.6$ & $0.012^{*}$ \\
\hline & female & reference & $\mathrm{N} / \mathrm{A}$ & $\mathrm{N} / \mathrm{A}$ \\
\hline \multirow[t]{4}{*}{ Education } & none & none & none & none \\
\hline & primary \& secondary school & reference & $\mathrm{N} / \mathrm{A}$ & N/A \\
\hline & high school & 0.5 & $0.1-1.9$ & 0.307 \\
\hline & college/university or more & 11.8 & $3.0-47.0$ & $<0.001^{*}$ \\
\hline
\end{tabular}

Table 4. Summary of perception and knowledge about aflatoxins from six provinces.

Question

Are moulds harmful to human and animal health?

Do your cereals ever get mouldy?

Has any member of your family gotten ill following consumption of mouldy food?

Has any of your animals gotten ill following consumption of mouldy food?

Can aflatoxins be present in milk?

Is milk from animals fed mouldy feed unsafe for human consumption?

Is meat from animals fed mouldy feed unsafe for human consumption?

Would your customers pay more for certified aflatoxin free milk?

\begin{tabular}{lrl} 
Answer & & \\
\hline Yes (\%) & No (\%) & Don't know (\%) \\
& & \\
79.89 & 20.10 & \\
58.51 & 41.49 & \\
12.32 & 87.68 & \\
6.34 & 93.66 & \\
10.33 & 9.96 & 79.71 \\
27.54 & 36.23 & 36.23 \\
27.17 & 37.14 & 35.69 \\
18.12 & 16.49 & 65.40
\end{tabular}


The climate in Vietnam can be distinguished into three different zones - North, South and Central. The North is humid and subtropical, while South is a tropical climate all year round. Central is between them. These climate conditions are favourable to mould development, particularly in the wet season (Cotty et al., 1994; Wu et al., 2011). It has been suggested that an increase in temperature and rainfall may increase mycotoxin production for stored maize (Magan and Aldred, 2007; Sandris and Magan, 2004). In southern Vietnam (including An Giang, Dak Lak and Dong Nai), maize is harvested twice a year (middle of year and end of the rainy season) (Thieu et al., 2008). The harvested maize is often sun dried or charcoal dried for storage. However, this process can be delayed or skipped after harvesting due to the large quantities and limited human resources or equipment. In this case, maize is more likely to be associated with aflatoxin. Interestingly, Dak Lak showed significantly lower positive rates compared to Dong Nai and An Giang with high positive rates. A potential explanation is that Dak Lak is located in the central highlands, ranging in altitude from 500 to $800 \mathrm{~m}$, thereby average temperature is from 15 to $20^{\circ} \mathrm{C}$, which is relatively cooler throughout the year compared to Dong Nai and An Giang $\left(27-32^{\circ} \mathrm{C}\right)(\mathrm{GSO}, 2016)$. Therefore, it is assumed that these conditions are not as favourable for aflatoxin production.

The main limitation of this study was that our samples were collected during the dry season (from January to April). Therefore, it may not be representative of samples in the wet season. In addition, most of samples were collected from households that were easily accessible and may not represent less accessible households.

In Vietnam, few studies have been conducted to evaluate the effects of aflatoxins on human and animal health. Therefore, further research will be needed for human and animal health risk assessments (including dietary surveys) of aflatoxins as well as conducting a study for control strategies. This is the first study to report perception and knowledge of aflatoxins in Vietnam. Study participants from southern Vietnam (An Giang, Dak Lak and Dong Nai) showed relatively higher awareness (question: Have you heard about aflatoxins?) compared to other provinces, and thus it might be worthwhile to further investigate what the main reasons are. Interestingly, we found that higher awareness was not linked to low positive rates of aflatoxins. For example, An Giang had the higher positive rate for food in spite of also having a study population with high awareness of aflatoxins. Therefore, in order to reduce the exposure and negative impact of aflatoxins, it is also important that people put the awareness and knowledge into action. The intervention program may include timing of planting, proper irrigation and pest management for preharvest, dried properly, moisture, insect and rodent control for post-harvest storage and hand sorting, winnowing and washing for post-harvest food preparation. While knowledge and awareness of aflatoxins and the means to control them may help change behaviour, there may be need for additional incentives such as premiums for aflatoxin-low products.

Younger age groups were more likely to have high awareness of aflatoxins while it was difficult to explain why awareness was lower for age group 40-49. Overall, males, highly educated people and farm workers were more likely to know about aflatoxins. It is well known that Vietnamese women continue to face big challenges, including poverty, limited access to higher education and discriminatory attitude and behaviours which was consistent with our findings (Schuler et al., 2006). Interestingly, most participants did not know that aflatoxins are harmful to human and animal health. Based on our results, we see the importance of targeting women and uneducated farmers for raising public awareness of aflatoxins.

In Vietnam, maize is the second most important crop after rice (Dinh Thao et al., 2004). It can be used as an alternative to rice during a rice shortage, especially amongst minority groups who live in rural areas and mountainous regions. In addition, maize is the main source for feeding pigs which accounts for about $70 \%$ of all livestock production in Vietnam (Lemke et al., 2008). However, aflatoxins are still not recognised as a major public health issue. Therefore, we believe that this analysed information can be useful to better understand the epidemiology of aflatoxins in different provinces. This study also produces evidence on potential risk to humans and animals in Vietnam as well as demographic factors (such as gender and level of education) significantly influencing knowledge of aflatoxins which is consistent with previous research (Jolly et al., 2009). In addition, aflatoxins can be potentially found in a wide range of agricultural products including cassava, peanuts, cereals, rice and nuts (Sangare-Tigori et al., 2006; Thieu et al. 2008). Therefore, in order to assess the total exposure to aflatoxins in humans and animals, it is necessary to investigate the levels of aflatoxins in these agricultural products in the future.

\section{Conclusions}

In conclusion, this study has found the presence of $\mathrm{AFB}_{1}$ in maize and a low awareness among farmers. This points to a need to further increase awareness-raising efforts in the public, taking into account the need to target women particularly, and also to conduct more research in the region. 


\section{Acknowledgements}

The authors thank the staff of sub-department of Plant Protection from 6 provinces for the collaboration with research team in conducting this study. We thank Dr. Duong Minh Tu from Plant Protection Department (PPD), Ministry of Agriculture and Rural Development (MARD) for his advice and contribution. We also thank other staff from Plant Protection Research Institute (PPRI) under the MARD for implementing data collection and laboratory analysis. This study was completed in ILRI-Vietnam office and supported by a grant from the CGIAR Research Program on Climate Change, Agriculture and Food Security (CCAFS) to the project Pestforecast ('surveillance and early warning systems for climate-sensitive diseases in Vietnam') and CGIAR CRP Agriculture for Nutrition and Health (A4NH) led by IFPRI.

\section{References}

Abbas, H.K., Cartwright, R.D., Xie, W. and Shier, W.T., 2006. Aflatoxin and fumonisin contamination of corn (maize, Zea mays) hybrids in Arkansas. Crop Protection 25: 1-9.

Abbas, H.K., Williams, W.P., Windham, G.L., Pringle, H.C., Xie, W. and Shier, W.T., 2002. Aflatoxin and fumonisin contamination of commercial corn (Zea mays) hybrids in Mississippi. Journal of Agricultural and Food Chemistry 50: 5246-5254.

Bennett, J.W. and Klich, M., 2003. Mycotoxins. Clinical Microbiology Reviews 16: 497-516.

Binder, E., Tan, L., Chin, L., Handl, J. and Richard, J., 2007. Worldwide occurrence of mycotoxins in commodities, feeds and feed ingredients. Animal Feed Science and Technology 137: 265-282.

Carvajal, M., Rojo, F., Mendez, I. and Bolanos, A., 2003. Aflatoxin B and its interconverting metabolite aflatoxicol in milk: the situation in Mexico. Food Additives and Contaminants 20: 1077-1086.

Cotty, P., Bayman, P., Egel, D. and Elias, K., 1994. Agriculture, aflatoxins and Aspergillus. In: Powell, K.A., Renwick, A. and Peberdy, J.F. (eds.) The genus Aspergillus. From taxonomy and genetics to industrial application. Springer, Berlin, Germany, pp. 1-27.

Devegowda, G., Raju, M., Afzali, N. and Swamy, H., 1998. Mycotoxin picture worldwide: novel solutions for their counteraction. Feed Compounder 18(6): 22-27.

Dinh Thao, T., Tri Khiem, N., Xuan Trieu, M., Gerpacio, R. and Pingali, P., 2004. Maize in Vietnam: production systems, constraints, and research priorities. CIMMYT, Mexico, Mexico.

Eaton, D.L. and Groopman, J.D., 2013. The toxicology of aflatoxins: human health, veterinary, and agricultural significance. Academic Press, San Diego, CA, USA.

European Commission (EC), 2006. Commission Regulation (EC) No 1881/2006 of 19 December 2006 setting maximum levels for certain contaminants in foodstuffs. Official Journal of the European Union L 364: 5-24.

Food and Agriculture organization (FAO), 2004. Worldwide regulations for mycotoxins in food and feed in 2003. FAO, Rome, Italy.
Food and Drug Administration (FDA), 2015. CPG Sec. 683.100 Action Levels for Aflatoxins in Animal Feeds. Available at: http://tinyurl. $\mathrm{com} / \mathrm{m} 64 \mathrm{p} 2 \mathrm{tg}$.

Food Safety Institute (FSI) Vietnam, 2011, National technical regulation on the limits of mycotoxins contamination in food. Available at: http://tinyurl.com/za2j2b9.

General Statistics Office (GSO), 2016. General Statistics Office of Viet Nam. Available at: https://www.gso.gov.vn/Default_ en.aspx?tabid $=491$.

Goto, T., Wicklow, D.T. and Ito, Y., 1996. Aflatoxin and cyclopiazonic acid production by a sclerotium-producing Aspergillus tamarii strain. Applied and Environmental Microbiology 62: 4036-4038.

Henry, S.H., Bosch, F.X. and Bowers, J., 2002. Aflatoxin, hepatitis and worldwide liver cancer risks. In: Jonathan, W., DeVries, J.W., Trucksess, M.W. and Jackson, L.S. (eds.) Mycotoxins and food safety. Advances in experimental medicine and biology volume 504. Springer, Berlin, Germany, pp. 229-233.

Henry, S.H., Bosch, F.X., Troxell, T.C. and Bolger, P.M., 1999. Reducing liver cancer - global control of aflatoxin. Science 286: 2453-2454.

Hosmer, D.W., Hosmer, T., Le Cessie, S. and Lemeshow, S., 1997. A comparison of goodness-of-fit tests for the logistic regression model. Statistics in Medicine 16: 965-980.

International Agency for Research on Cancer (IARC), 2002. Aflatoxins. In: Monograph on the evaluation of carcinogenic risks to humans. Vol. 82. Some traditional herbal medicines, some mycotoxins, naphthalene and styrene. IARC, Lyon, France, pp. 171-300.

Jolly, C.M., Bayard, B., Awuah, R.T., Fialor, S.C. and Williams, J.T., 2009. Examining the structure of awareness and perceptions of groundnut aflatoxin among Ghanaian health and agricultural professionals and its influence on their actions. Journal of Socio-Economics 38: 280-287.

Klich, M., Mullaney, E., Daly, C. and Cary, J., 2000. Molecular and physiological aspects of aflatoxin and sterigmatocystin biosynthesis by Aspergillus tamarii and A. ochraceoroseus. Applied Microbiology and Biotechnology 53: 605-609.

Lemke, U., Mergenthaler, M., Roßler, R., Huyen, L., Herold, P., Kaufmann, B. and Zarate, A.V., 2008. Pig production in Vietnam - a review. CAB Reviews: Perspectives in Agriculture, Veterinary Science, Nutrition and Natural Resources 23: 1-15.

Lewis, L., Onsongo, M., Njapau, H., Schurz-Rogers, H., Luber, G., Kieszak, S., Nyamongo, J., Backer, L., Dahiye, A.M. and Misore, A., 2005. Aflatoxin contamination of commercial maize products during an outbreak of acute aflatoxicosis in eastern and central Kenya. Environmental Health Perspectives 113: 1763-1767.

Magan, N. and Aldred, D., 2007. Post-harvest control strategies: minimizing mycotoxins in the food chain. International Journal of Food Microbiology 119: 131-139.

Mohammadi, H., 2011. A review of aflatoxin $M_{1}$, milk, and milk products. In: Guevara-Gonzalez, R.G. (ed.) Aflatoxins biochemistry and molecular biology. INTECH Open Access Publisher, Rijeka, Croatia, pp. 397-414.

Peraica, M., Radic, B., Lucic, A. and Pavlovic, M., 1999. Toxic effects of mycotoxins in humans. Bulletin of the World Health Organization 77: 754-766. 
Pitt, J., Wild, C., Baan, R.A., Gelderblom, W.C.A., Miller, J.D., Riley, R.T. and Wu, F., 2012. Improving public health through mycotoxin control. IARC Scientific Publication No. 158. IARC, Lyons, France.

Richard, J.L., 2007. Some major mycotoxins and their mycotoxicoses An overview. International Journal of Food Microbiology 119: 3-10.

Roebuck, B.D. and Maxuitenko, Y.Y., 1993. Biochemical mechanisms and biological implications of the toxicity of aflatoxins as related to aflatoxin carcinogenesis. In: Eaton, D.L. and Groopman, J.D. (eds.) The toxicology of aflatoxins: human health, veterinary and agricultural significance. Academic Press, San Diego, CA, USA, pp. 27-43.

Rustom, I.Y., 1997. Aflatoxin in food and feed: occurrence, legislation and inactivation by physical methods. Food Chemistry 59: 57-67.

Sandris, V. and Magan, N., 2004. Environmental profiles for growth and mycotoxin production. In: Magan, N. and Olsen, M. (eds.) Mycotoxins in food: detection and control. Woodhead Publishing Ltd., Cambridge, UK, pp. 174-189.

Sangare-Tigori, B., Moukha, S., Kouadio, H.J., Betbeder, A.M., Dano, D.S. and Creppy, E.E., 2006. Co-occurrence of aflatoxin $B_{1}$, fumonisin $B_{1}$, ochratoxin $A$ and zearalenone in cereals and peanuts from Côte d'Ivoire. Food Additives and Contaminants 23: 1000-1007.

Schuler, S.R., Anh, H.T., Ha, V.S., Minh, T.H., Mai, B.T.T. and Thien, P.V., 2006. Constructions of gender in Vietnam: in pursuit of the 'three criteria'. Culture, Health and Sexuality 8: 383-394.

Smith, J.E., Solomons, G., Lewis, C. and Anderson, J.G., 1995. Role of mycotoxins in human and animal nutrition and health. Natural Toxins 3: 187-192.
Thieu, N.Q., Ogle, B. and Pettersson, H., 2008. Screening of aflatoxins and zearalenone in feedstuffs and complete feeds for pigs in Southern Vietnam. Tropical Animal Health and Production 40: 77-83.

Trung, T., Bailly, J., Querin, A., Le Bars, P. and Guerre, P., 2001. Fungal contamination of rice from south Vietnam, mycotoxinogenesis of selected strains and residues in rice. Revue de Médecine Vétérinaire 152: 555-560.

Trung, T., Tabuc, C., Bailly, S., Querin, A., Guerre, P. and Bailly, J., 2008. Fungal mycoflora and contamination of maize from Vietnam with aflatoxin $B_{1}$ and fumonisin $B_{1}$. World Mycotoxin Journal 1: 87-94.

Wang, D.S., Liang, Y.X., Chau, N.T., Dien, L.D., Tanaka, T. and Ueno, Y., 1995. Natural co-occurrence of Fusarium toxins and aflatoxin $B_{1}$ in corn for feed in North Vietnam. Natural Toxins 3: 445-449.

Williams, J.H., 2011. Aflatoxin as a public health factor in developing countries and its influence on HIV and other diseases. Human aflatoxicosis in developing countries: a review of toxicology, exposure, potential health consequences and interventions. Peanut Collaborative Research Support Program, University of Georgia, GA, USA.

Williams, J.H., Phillips, T.D., Jolly, P.E., Stiles, J.K., Jolly, C.M. and Aggarwal, D., 2004. Human aflatoxicosis in developing countries: a review of toxicology, exposure, potential health consequences, and interventions. American Journal of Clinical Nutrition 80: 1106-1122.

Wu, F., Bhatnagar, D., Bui-Klimke, T., Carbone, I., Hellmich, R., Munkvold, G., Paul, P., Payne, G. and Takle, E., 2011. Climate change impacts on mycotoxin risks in US maize. World Mycotoxin Journal 4: 79-93. 